\title{
Maternal and Fetal Outcome of Elective Caesarean Section at 37 - 38 Weeks versus 39 Completed Weeks of Gestation in Enugu, Southeast Nigeria
}

\author{
OKEKE TC ${ }^{1, *}$, ONAH N ${ }^{1}$, IKEAKO LC ${ }^{2}$, EZENYEAKU CCT ${ }^{2}$, NWOGU-IKOJO E ${ }^{1}$ \\ ${ }^{1}$ Department of Obstetrics \& Gynaecology, Uuniversity of Nigeria Teaching Hospital (Unth), Enugu, Nigeria \\ ${ }^{2}$ Department of Obstetrics and Gynaecology, Anambra State University Teaching Hospital Awka, Nigeria \\ *Corresponding author: ubabiketochukwu@yahoo.com
}

Received January 15, 2013; Revised April 19, 2013; Accepted April 23, 2013

\begin{abstract}
A retrospective study comparing maternal and neonatal outcome of singleton fetuses delivered at 37-38 weeks of completed gestation with those delivered at 39 completed weeks of gestation or longer by elective caesarean section at the University of Nigeria Teaching Hospital, Enugu between January 1, 2004 and December 31, 2008. There were 164(21.3\%) elective caesarean deliveries during the study period. $117(71.3 \%)$ were performed between 37-38 weeks of completed gestation and $47(28.7 \%)$ at 39 completed weeks of gestation. Elective caesarean births at 37-38 weeks were associated with significantly higher rates of admission to the neonatal care unit, neonatal jaundice, and a higher proportion of newborns with Apgar score $<6$ at 5minutes. As a result of increased morbidity and iatrogenic prematurity in the developing countries due to elective caesarean delivery at 37-38weeks associated with increased cost of admissions in the newborn special care units, elective caesarean delivery should be advised at or after 39 weeks of gestation unless there is evidence of fetal lung maturity. At 39 completed weeks of gestation, elective caesarean delivery is associated with better fetal outcomes than at 37-38 weeks of completed gestation.
\end{abstract}

Keywords: maternal outcome, fetal outcome, elective caesarean section, gestational age, Enugu-Nigeria.

\section{Introduction}

Elective caesarean section is a planned caesarean section performed on pregnant woman for either maternal or fetal indications before the onset of labour [1,2]. Caesarean sections in low resource areas pose challenges to clinicians [3]. Fetal outcome following caesarean section is a serious concern [2,3]. Caesarean delivery has been shown to be a safe procedure for both the mother and fetus $[4,5]$.

The incidence of caesarean deliveries at the University of Nigeria Teaching Hospital is $25 \%$ with elective caesarean section constituting $21.3 \%$ of all caesarean deliveries [6]. There is a growing opinion that elective caesarean section should not be done before 38 weeks unless there is evidence of fetal lung maturity to avoid adverse neonatal outcomes [7]. Several studies have documented high incidence of respiratory problem, the newborn special care unit admission, prolonged hospitalization, low Apgar score, iatrogenic prematurity, surfactant deficiency, and transient tachypnoea of newborn $[8,9,10,11,12]$, following elective caesarean delivery. Studies done in United States, more than one third of elective caesarean deliveries at term were performed before 39 weeks gestation [13]. The neonatal outcome at 37-38 weeks was compared with neonatal outcome at 39 weeks gestation and it was shown that deliveries at 37-38 weeks were associated with adverse neonatal outcomes such as neonatal death, neonatal sepsis, respiratory complication and admissions into the Newborn Special Care Unit (NBSCU) as compared to delivery at 39 completed weeks of gestation and delaying delivery beyond 42 weeks was also associated with increased rates of neonatal adverse outcomes [13].

This study was a pioneer study on the maternal and fetal outcome of elective caesarean section at 37-38 weeks versus 39 completed weeks of gestation in Enugu, South East, Nigeria.

\section{Method}

A 5-year retrospective study of obstetrics theatre register of University of Nigeria Teaching Hospital Enugu between January 1, 2004 and December 31, 2008 was carried out. At surgery, the pediatricians (neonatologists) were present.

The medical records were reviewed by trained staff using pre-established data extraction forms. The records of women who had elective caesarean deliveries for singleton pregnancies during the study period were retrieved and data extracted. The data extracted include maternal age, parity, and neonatal outcomes like admission to the Newborn Special Care Unit (NBSCU) (defined as any length of time spent in the NBSCU after delivery), Apgar scores at 5 minutes, neonatal jaundice and perinatal death. 
Maternal and neonatal outcomes of elective caesarean deliveries at 37-38 completed weeks of gestation were compared with elective caesarean deliveries at 39 completed weeks of gestation or longer using chi-square test at $95 \%$ confidence level. P-values less than 0.05 were considered significant. The data were analyzed using SPSS version 12 .

Booked patients were those who had registered for formal antenatal care at UNTH, while unbooked patients were those who had not registered.

\section{Result}

A total of 3078 deliveries were undertaken during the study period. Caesarean section accounted for 770 deliveries giving an incidence of $25.0 \%$. A total of 606 $(78.7 \%)$ caesarean sections were done as emergencies, while $164(21.3 \%)$ were done as elective caesarean section for singleton pregnancies. During the study period, 117 (71.3\%) caesarean section were performed between 37-38 completed weeks of gestation and $47(28.7 \%)$ at 39 completed weeks of gestation or longer.

All the patients for elective caesarean section were booked patients of the hospital. Thirty seven women (22.6\%) had no formal education, 30 women $(18.3 \%)$ had primary education, $20(12.2 \%)$ had secondary education while 77 women $(47 \%)$ had tertiary education.

The main indications for elective caesarian section in this study were illustrated in Table 1.

Table 1. Indications for elective caesarean section at 37-38 weeks and at 39 weeks gestational age

\begin{tabular}{|c|c|c|}
\hline Indication & Frequency & Percentages \\
\hline Previous caesarean section & 71 & 43.3 \\
\hline Breech presentation & 24 & 14.6 \\
\hline Abnormal lie & 28 & 17.1 \\
\hline $\begin{array}{c}\text { Elderly primigravida } \\
+(\text { infertility) }\end{array}$ & 8 & 4.9 \\
\hline Caesarean section on request & 10 & 6.1 \\
\hline Cephalopelvic disproportion & 23 & 14.0 \\
\hline Total & 164 & 100 \\
\hline
\end{tabular}

Three $(1.8 \%)$ admissions into the newborn special care unit were recorded among women who had caesarean delivery at 39 weeks while $37(22.6 \%)$ admissions were for those women who had elective caesarean delivery at 37-38 completed weeks. The difference was statistically significant $(\mathrm{P}=0.005)$. No neonatal jaundice was recorded among women who had elective caesarean delivery at 39 weeks while $19(11.6 \%)$ cases of neonatal jaundice were recorded for the women that had elective caesarean delivery at 37-38 completed weeks. The difference was statistically significant $(\mathrm{P}=0.002)$. No neonatal death was recorded among women who had elective caesarean delivery at 39 completed weeks while those who had elective caesarean delivery at 37-38 completed weeks recorded $1(0.6 \%)$ neonatal death. The difference was not statistically significant $(\mathrm{P}=1.000)$. There was no significant difference between the proportion of newborns with low Apgar scores in both groups $(\mathrm{P}=0.182)$. No maternal death was recorded in both groups. Table 2 summarizes these. Table 3 and Table 4 summarize the literacy level of the patients and the age distribution of the patients that had elective caesarean section respectively.
The parity of the patients allowed elective caesarean section was illustrated in Table 5.

Table 2. Maternal and neonatal outcomes following elective caesarean section

\begin{tabular}{|c|c|c|c|}
\hline Outcome & $\begin{array}{c}37-38 \text { weeks } \\
(\mathrm{N}=117)\end{array}$ & $\begin{array}{c}39 \text { weeks } \\
(\mathrm{N}=47)\end{array}$ & $\begin{array}{c}\text { P-Value } \\
\text { (Fischer } \\
\text { exact test })\end{array}$ \\
\hline Perinatal death & $1(0.6 \%)$ & $0(0 \%)$ & 1.000 \\
\hline $\begin{array}{c}\text { Low Apgar } \\
\text { score* }\end{array}$ & $11(6.7 \%)$ & $1(0.6 \%)$ & 0.182 \\
\hline Maternal death & $0(0 \%)$ & $0(0 \%)$ & - \\
\hline Jaundice & $19(11.6 \%)$ & $0(0 \%)$ & 0.002 \\
\hline $\begin{array}{c}\text { Admission into } \\
\text { NICU }\end{array}$ & $37(22.6 \%)$ & $3(1.8 \%)$ & 0.005 \\
\hline
\end{tabular}

* N.B: Apgar score <6 is low Apgar scores in Nigeria.

Table 3. Literacy level of patients

\begin{tabular}{|c|c|c|}
\hline Literacy & Frequency & Percentages \\
\hline No formal education & 37 & 22.5 \\
\hline Primary education & 30 & 18.3 \\
\hline Secondary education & 20 & 12.2 \\
\hline Tertiary education & 77 & 47.0 \\
\hline Total & 164 & 100 \\
\hline
\end{tabular}

Table 4. Age distribution

\begin{tabular}{|c|c|c|}
\multicolumn{3}{|c}{ Table 4. Age distribution } \\
\hline Age & Frequency & Percentage \\
\hline $15-19$ & 5 & 3 \\
\hline $20-24$ & 7 & 4.3 \\
\hline $25-29$ & 31 & 18.9 \\
\hline $30-34$ & 53 & 32.3 \\
\hline $35-39$ & 32 & 19.5 \\
\hline $40-44$ & 18 & 11 \\
\hline Not stated & 18 & 11 \\
\hline Total & 164 & 100 \\
\hline
\end{tabular}

Table 5. Parity of patients who had elective caesarean section.

\begin{tabular}{|c|c|c|}
\hline Parity & Frequency & Percentage \\
\hline 0 & 10 & 6.1 \\
\hline 1 & 33 & 20.1 \\
\hline 2 & 35 & 21.3 \\
\hline 3 & 29 & 17.7 \\
\hline 4 & 21 & 12.8 \\
\hline 5 & 1 & 0.6 \\
\hline$>6$ & 8 & 4.9 \\
\hline Not stated & 27 & 16.5 \\
\hline Total & 164 & 100 \\
\hline
\end{tabular}

\section{Discussion}

Caesarean section rates continue to rise globally both in developed and developing countries [1,3]. In an effort to reduce the iatrogenic prematurity associated with elective caesarean section, American College of Obstetricians and Gynecologists recommends scheduling elective caesarian section at 39 weeks or later based on menstrual dates and first trimester ultrasound [13]. In this study, more than two-thirds $(71.3 \%)$ of elective caesarean deliveries at term were performed before 39 completed weeks of gestation compared to the Netherlands where $56.6 \%$ of elective caesarean section were done before 39 completed weeks of gestation [14]. In a study in the United States on the 
timing of elective repeat caesarean delivery at term, Tita et al. [15], found that $35.8 \%$ of elective repeat caesarean section was performed below 39 completed weeks of gestation, much lower than the finding in this study. The rates of elective caesarean delivery before 39 weeks were higher in the European cohorts, (ranging from 51 to 83\%) [16] which is similar to this study $(71.4 \%)[16,17]$.

This study showed that significantly higher proportions of cases of neonatal jaundice were admitted into the NBSCU $(p=0.005)$ and neonatal jaundice was observed among elective caesarean deliveries at $37 / 38$ completed weeks than among those at 39 completed weeks of gestation $(\mathrm{p}=0.002)$. Thus, delaying caesarean section until after 39 completed weeks of gestation will give the liver more time to mature to enable it better handle bilirubin conjugation and excretion. Wilmink et al. [14] in their study in Netherlands, also reported higher incidences of hyperbilirubinaemia in neonates delivered by elective caesarean section at 37-38 completed weeks of gestation compared to those delivered at 39 completed weeks of gestation or longer.

There was only one perinatal death in this study and it occurred among the 37-38 weeks group as a result of severe asphyxia. The risk of unexplained still birth has been reported to be no greater than 0.2 of 1000 births at 37 weeks and 0.5 of 1000 births at 38 weeks among Scottish and Canadian cohorts of women who had previous caesarean delivery [18]. The observed low perinatal mortality rate following elective caesarean section in this study was comparable with reports from another study done in Nigeria [5]. This low perinatal mortality rate in this study can be explained by the fact that women who undergo elective caesarean delivery are usually those formally booked in the teaching hospital for antenatal care. In this study previous caesarean section was the commonest indication for elective caesarean section followed by malpresentation and abnormal lie.

These deliveries at 37-38 completed weeks of gestation were associated with a preventable increase in neonatal morbidity and admission to the Newborn Special Care Unit. There may be need to delay elective caesarean delivery until 39 completed weeks of gestation because of the associated medical and economic benefits.

\section{Disclosure of Interest}

The authors report no conflicts of interest. The authors are responsible for the content and writing of the paper.

\section{References}

[1] NIH "state-of-the science conference statement; caesarean delivery on maternal request" Obstet Gynecol. 2006; 107:1386-97.

[2] Hook B, AMIM, SB, Hack M; neonatal morbidity after elective repeat caesarean section and trial of labour. Pediatrics, 1997; 100(3): 348-353.

[3] Kwei A, Cohlem BJ, Kanhai H, H, Bruiuse HW, Visser $\mathrm{GH}: 3 \mathrm{pt}$ :348-caesarean section on request; a survey in the Netherlands eurj Obstetrics and Gynecology report book 2004 April 15;113(2):186-90.

[4] Kamath B, James K, Glazre JE, Anneni: neonatal, outcomes after elective caesarean delivery: Obstet and Gynecol June 2009; 113(1886):1231-1238.

[5] Onankpa B, Ekele BI. Neonatal outcome following caesarean section in University Teaching Hospital Sokoto, J Natl Med Assoc 2009; 101(6): 578-581.

[6] Okezie AO, Oyefara B, Chigbu CO. A 4-year analysis of caesarean delivery in a Nigerian teaching hospital: One quarter of babies born surgically: J Obstet, Gynaecol 2007; 27(5):470-4.

[7] Treffers SP: The rising for caesarean birth BMJ. 1993; 307:10171019.

[8] Yee W, Aminu H, Wood Selective caesarean delivery, neonatal intensive care unit admission and neonatal respiratory distress BMJ 1994:308:2036-2038.

[9] Alder Dice F, MCCall E, Bailie C: Admission to neonatal intensive care with respiratory morbidity, following 'term' elective caesarean sectioning. Irish Med J 2005:98-170.

[10] Erch J, Roth-Kleiner M, Baekam P: Increasing incidence of respiratory distress in neonatal, Accra pediatrics 2007:1577.

[11] Donaldson SF, Dagbjatson H; Respiratory dysfunction in infants born by caesarean section without labour. Journal Lacknabladid 2007:93-625.

[12] Smith JF, Ifernandez C, Wat JR: Fetal laceration, injury at caesarian delivery; Obstet and Gynecol 1997; 90:344-346.

[13] Laye MR, Dellinger EIT: Timing scheduled caesarean delivery in patients on a teaching versus private service: Adherence to American College of Obstetrician and Gynecologists guideline and neonatal outcome: Am J Obstet Gynecol 2006; 193:377-584.

[14] Wilmink FA, Hukkelhoven CW, Lunshof S, Mol BWJ, van der Post JAM,Papatsonis DNM. Neonatal outcome following elective cesarean section beyond 37 weeks of gestation: a 7-year retrospective analysis of a national registry. Am J Obstet Gynecol.2010; 202:250.e1-8.

[15] Tita ATN, Landon MB, Spong CY, Lai Y, Leveno KJ, Varner MW, et al. Timing of elective cesarean delivery at term and neonatal outcomes. New Engl J Med. 2009; 360:111-120.

[16] Dobson R: Caesarean section rate in England and walehits $21 \%$ Brit Med J 2001; 323: 951a.

[17] Grazrosi GC, Bakker CM, Brouwers AA, Bruiseer HW. Elective caesarean section is preferred after, the completion of a minimum of 38weeks of pregnancy. Tijdschr Geneeskd 1998:142; 23002303.

[18] Wood SL, Chla S, Ross S, Sauve R. The risk unexplained ante partum still birth in secondary pregnancies following caesarian section in the first pregnancy. BJOG 2008; 115: 726-731. 